\title{
Designing 'Embodied' Science Learning Experiences for Young Children
}

\author{
Rhiannon Thomas Jha ${ }^{[1]}$ Sara Price ${ }^{[1]}$ and Alison Motion ${ }^{[2]}$ \\ ${ }^{1}$ University College London, 23-29 Emerald St, London WC1N 3QS, UK \\ ${ }^{2}$ Learning Through Landscapes, Monarch Way, Winchester SO22 5PW, UK \\ sara.price@ucl.ac.uk
}

\begin{abstract}
Research in embodied cognition emphasises the importance of meaningful 'bodily' experience, or congruent action, in learning and development [1]. This highlights the need for evidence-based design guidelines for sensorimotor interactions that meaningfully exploit action-based experiences, that are instrumental in shaping the way we conceptualise the world. These sensorimotor experiences are particularly important for young children as they can provide them with an embodied toolkit of resources (independent of language skills or subject specific vocabulary) that they can draw upon to support science 'think' and 'talk', using their own bodies to develop and express ideas through gesture, that are grounded on sensorimotoric representations from action experiences. Taking an iterative design-based research (DBR) approach [2], this paper reports the design, development and deployment of a programme of outdoor activities for children aged 4-6 years, that drew on embodied cognition theory to foster meaningful action in relation to ideas of air resistance. This research is relevant to researchers, practitioners and designers. It makes a contribution to learning experience design by making explicit the process of applying key components of embodied cognition theory to the design of science learning activities for early years, and how this can effectively inform digital design.
\end{abstract}

Keywords: Embodied cognition, Early years science, Digital design.

\section{$1 \quad$ Introduction}

Opportunities for early years science education are expanding due in part to advancements in technology, ongoing research in embodied cognition, increased value being placed on the importance of early intervention by both researchers and educators [3] and increasing awareness of the breadth of educational experiences which need to be nurtured. However, identifying the best tools and pedagogy can often be challenging, and there remains a relative lack of research demonstrating how to translate research in domains like embodied cognition into practice, and how best to assess the effectiveness of this translation.

Science learning from pre-school onwards is typically centred around hands-on interactive activities that utilise visual prompts, objects or apparatus to demonstrate and 
provide concrete sensorimotor experience of science concepts. Much of this involves observation and noticing visuo-spatial features related to action experience, with activity design focusing on the objects of science, rather than perhaps the broader embodied activities that might surround these. Alongside this, there is a call to better engage children in outdoor play and learning, where there are increased opportunities for designing for embodied movement and physical activities. Children's movement is a foundation for much of child development, yet is often overlooked [4]. Research in embodied cognition emphasises the importance of 'meaningful' movements and bodily experience in learning and development [e.g. 5, 6, 7, 1]. These perceptual and sensorimotor experiences are particularly important for young children as they can provide them with an embodied toolkit of resources (independent of language skills or subject specific vocabulary) that they can draw upon to support science 'think' and 'talk', using their own bodies to develop and express ideas through gesture, that are grounded on sensorimotoric representations from action experiences [e.g. 8, 9, 10, 11]. Embodied movement and physical activities also contribute to the effective development of physical literacy [e.g. 4] and thus provide both new ways of engaging with science ideas, as well as the more general, but significant, physical literacy skills. Thus, our interactions with the world are significant in our development generally, but also can be drawn on in creating interactions with the world that offer 'lived' experiences relevant to science ideas. "Outdoor play also engages children in physical learning through exploratory experiences which engage them meaningfully, purposefully and with imagination in more extensive and natural environments than can normally be provided indoors [4, p.113].

However, framing the design of early years science activities from such an embodied perspective is relatively new for educational practitioners and digital design, and calls for more theoretically and empirically grounded embodied design guidelines for sensorimotor interactions that meaningfully exploit action-based experiences, for early years educators and designers. Taking an iterative design-based research (DBR) approach [2] this paper reports the design, development and deployment of a programme of outdoor activities for children aged 4-6 years, that drew on embodied cognition theory to foster meaningful action in relation to the science idea of air resistance. Drawing specifically on the following ideas from embodied cognition theory: movement (relating to 'felt'/tacit/kinaesthetic experience); meaning congruency [12], and integrated physical learning tasks [13], we designed activities that provided differently embodied experiences to support engagement with ideas of air resistance, and exploited the outdoors, by drawing on environmental characteristics of space, airflow and outdoor objects (e.g. wearable resistance parachutes) as well as bodily forms of engagement.

\section{Theoretical Underpinning}

The design of the science learning activities presented here is situated within the context of Embodied Cognition. Theories of Embodied Cognition originate from diverse disciplines bringing various discourses around the role of the body in cognitive development. We situate this work within overarching ideas from enactive cognition where understanding is actively constructed by 'situated living bodies' [14], through dynamic 
interaction between body (taking into consideration its specific biological and physical affordances), environment and others $[15,16,10]$. Central to this is the idea that meaning and conceptual representation are grounded in perceptual and motor experience: "conceptual capacities incorporate and are structured in terms of patterns of bodily activity" [14]. This has important implications for how we design embodied learning activities for young children's science learning. In this work we draw on the following key ideas to inform our design:

\subsection{Movement (felt experience, tactile kinesthetic movement)}

Existentialist and phenomenologists notions of 'lived embodiment' or 'being in the world' claim that we make sense of the world based on the way we perceive it, and each experience, or perception, modifies or shapes our understanding of the world. While our embodied interactions with the world are significant in our development generally, we draw on this idea to create interactions with the world that offer 'lived, felt' experiences relevant to specific science ideas. There are two key related considerations that underpin our designs:

Firstly, a central component of 'lived embodiment' and interaction with the world is movement, which plays a critical role in cognition - it is through our movement that we interact with and experience and interpret the world [17]: meaning and thinking being closely linked to movement [18]. Movement capacities have been referred to as the 'ongoing axis of thought and knowing' [19]. Sheets-Johnson (1982) argues that from infancy we 'think in movement' - we learn about the world and our bodies through movement. These early experiences provide a foundation for the development of more complex notions of space and the world. Indeed, as adults we also experience space and the world through attention to movement and kinesthetic qualities when, for example, we walk into a strong wind, or push something heavy across the floor. "Kinesthesia is the gateway to those coordination dynamics that make the world familiar to us and allow us to know what to expect" [18, p. 173]. More than this, embodied interaction with particular objects or features of the world constitute the meaning or understanding we place on these: "As we move in relation to an object or feature in the world, we experience a particular embodied relationship with that feature. This relationship then becomes integral to our understanding of that feature" $[4, p .26]$.

Secondly, the lived experience - our everyday embodied interactions (movements) with the world - typically occurs at the unconscious level e.g. learning to walk, achieved through repeated trial and error or repeated practice. As adults, once we've mastered 'movement', this process often gets taken for granted ("we may no longer appreciate how thinking in movement informs our lives" Sheets-Johnson, 1982, p. 174) or fades into the unconscious [4], and while important is not necessarily brought to the foreground.

Our design aimed to bring children's awareness of these felt kinesthetic experiences, movements to the foreground in the context of science ideas, to provide links to key components of air resistance. Thus, one aim of our design was to bring to the fore important aspects of the 'typically unconscious lived experience' to develop an activity that brought children's awareness of their 'felt' experience of wind, drag or lift. 


\subsection{Meaning Congruency}

Building on the critical aspect of movement, we also draw on Hald's [12] notion of meaning congruency. Hald also holds the view that "our bodily actions make things happen, which in turn creates meaning" (2016, p. 497), but Hald identifies the important role of motor and perceptual experiences more broadly. While recent work in gesture studies framed within embodied cognition suggest the importance of congruent action for fostering learning [e.g. 1], Hald [12] proposes that a broader range of actions - or movements - are also instrumental in eliciting and interpreting changes in our environment, those changes being perceived through different sensory modalities. The notion of congruent action refers to a meaningful action that directly maps to a concept, for example, swinging the forearm with a fixed elbow to learn about a pendulum [1]. Research suggests that congruent actions provide important sensorimotor representations that children can use later through gesture to express and communicate these ideas. However, Hald's notion of 'meaningful' action highlights the role of our multisensory 'embodiment' and multisensory representations in fostering cognition (which links to Barsalou's model of perceptual processing). Recent work examining young children's gestural communication of science ideas, based on interaction with various objects in a water table, indeed shows ways in which children draw on their wider perceptual experiences - including what they observed based on their actions - to generate sensorimotor representations that they used to communicate through gesture about their experience [20]. What is important is the link between action and perception, and how we can design to enable children to make meaningful links between movement and their perceptual and sensorimotor experience.

We draw on these ideas in our design, by providing congruent perceptual, kinaesthetic and physical sensory experiences, using multiple modes of representation of air resistance through the different activities.

\subsection{Integrated Physical Learning Tasks}

Skulmowski and Rey's [13] review of research on embodied learning noted that the outcome of comparative studies typically showed better learning performance when the embodied learning designs involved 'integrated physical learning tasks', rather than incidental physical learning tasks. Integrated physical learning tasks refer to studies where embodiment aspects were inseparably connected to the learning task [13], for example, running to catch a baseball, as an example of learning to interact with projectile motion in the physical world. This aspect of Skulmowski and Rey's [13] work draws heavily on Wilson and Golonka's paper [21], which positions embodied research as a process of identifying the available resources an organism is actually using and how they are being coordinated into a smart, task-specific framing to solve the task at hand. Wilson and Golonka suggest that four key questions must be addressed in order for the role of embodied cognition to be explored within a research framework. Here we provide a brief overview of how these four questions helped us think through the design of the activities to ensure that they were embedded in physical learning.

1) What is the task to be solved? 
During science themed activities young children engage in exploration, which will help them to effectively interact with a given physical world as well as allowing them to better ingratiate themselves in a given social world. More specifically in each activity children will have a particular task, for example, when running whilst wearing a parachute children need to balance the forces exuded on their bodies to allow them to move forward with control, and to start and finish at predetermined points. When we ask children to hold ribbons and observe the effect of wind on their movement more specifically their task is to maintain grip on the ribbons under changing wind conditions.

2) What are the resources available to solve this task?

When designing our tasks, we considered the resources we were providing in the context of the role of the body, the brain and the environment as well as through the relationship between these - for example the motion of a body through the environment, and how this might change with different resources.

3) How can these resources be assembled to solve the task?

When designing our tasks, we considered how the different resources might be drawn upon in a dynamic task solving system, and what each contributes in terms of experiencing and thinking about air resistance.

4) Are these resources actually assembled and used?

Our research aims to address this question by exploring the extent to which children use the embodied resources provided by each activity to solve each task, and to identify key aspects that could be better supported through digital augmentation.

In summary, the design aimed to provide integrated physical learning tasks, that fostered 'felt' experiences, and provide meaning congruency through children's bodily movement and actions linked to broader multisensory and perceptual experiences. Our research aimed to explore whether and/or how children drew on these resources during each activity.

\section{$3 \quad$ Methodology - Design Based Research}

An iterative design-based research (DBR) approach [2] was taken to design, develop and deploy a programme of outdoor activities for children aged 4-6 years, that drew on key ideas from embodied cognition theory to foster meaningful action in relation to science concepts related to air resistance. Design based research aims to improve educational practice through theoretically driven iterative design, development and deployment of educational activities in real world settings, developed through researcher-practitioner collaboration, with a view to informing theory and/or generating design guidelines [2].

The methodology undertaken here reflects key characteristics of DBR [22]. The key focus of this work was to explore ways in which precepts from embodied cognition theory can be explicitly used to inform design of embodied science learning activities, with a view to productively inform digital augmentation design. The activity designs were, therefore, grounded on key precepts from Embodied Cognition theory, outlined above. An initial set of activity designs were developed through a collaborative partnership between embodied learning researchers and a charity that works with 
educational bodies to enrich, enhance and inspire young children's outdoor learning. These activities were iteratively designed and tested in an embodied learning intervention with children aged 4-6 years. The implementation of the designed activities took place in a primary school's outdoor playground adjacent to their classrooms, as part of the children's normal school day. Children engaged with the activities in pairs, selected by the teacher, and participated in a semi-structured interview afterwards. The activities were led by a researcher-practitioner pair who structured the tasks, provided practical support, engaged children in the tasks and prompted conversation around the activities. The interview aimed to allow children to express any observations, interactions, feelings and ideas which emerged from their interactions. Questions were structured around each of the activities and children were encouraged to describe what they did, what happened, what they could feel, what else they observed and how these sensations and observations differed under different circumstances (e.g. sizes of parachutes, wind levels, states of motion). Interviews were semi-structured to allow the researcher to respond to children's answers, with the aim of encouraging them to build on these responses. All interactions and interviews were video recorded for analysis. Multimodal transcripts were generated for interactions and interviews, capturing children's speech, gestures, gaze, and action. The learning interactions were evaluated in terms of the ways in which children made meaning, or not, from their embodied interaction, to inform a second, and then third iteration of designed activities. A final evaluation was undertaken to generate digital design ideas.

Evaluation of the effectiveness of the activities for communicating aspects of air resistance examined links between the designed perceptual motor experiences and children's communication of these ideas after their experience, undertaken in two ways:

- Through analysis of children's multimodal interactions during the activities exploring how they systematically used their bodies to explore and make meaning, whilst supported by the designed physical environment.

- Through analysis of children's gesturing in subsequent semi-structured interviews, where the physical environment was pared down and children could no longer directly incorporate the interactive objects into their communication. We chose to focus on gesture as this mode of communication has been established as a source of evidence for embodied cognition as it provides support for the idea that bodily experience assists children's thinking and communication across a number of domains, however gestures were always considered within the multimodal context of children's communication.

\section{Design Phase 1}

\subsection{Air Resistance}

As a collaborative team we discussed science themed topics which would particularly benefit from being situated outdoors, from being framed through an embodied lens and which children between 3 and 6 years-of-age would have had minimal formal exposure to, but which they could engage with through action and experience. We chose to design activities around the topic of air resistance. Any object in motion through air is 
subjected to a resistive force to that motion termed air resistance. This force is affected by variables including the surface area of the object and its speed of motion. Given their age, we did not have an expectation that children would emerge from the tasks with a concept of air resistance, but rather that these activities would provide complementary experiences which drew attention to the relationships/factors which underpin this concept, such as:

- Air is all around us

- When an object moves through air its movement is slowed by the air around it

- The shape and size of the object will influence the extent of this slowing 'force'

- Feeling the effect of this 'force' by moving objects through air, or by observing objects being moved by air

\subsection{Activity Designs}

In design phase 1 the experience consisted of three activities which were designed to provide different multisensory experiences with concepts of air resistance, specifically drawing on notions of 'felt' or tacit experiences, movement and other congruent perceptual experiences. The initial activities all made use of parachutes, as we anticipated that this surface level similarity would help children to link ideas across the activities. However, each activity was designed to provide children with different sensorimotor experiences that would enrich their 'embodied toolkit' of resources around the higher order concept of air resistance.

Table 1: Design Phase 1 - Sensory experiences mapped to potential learning outcomes

\begin{tabular}{|l|l|l|}
\hline Activity & Key sensory experience & Potential learning outcomes \\
\hline $\begin{array}{l}\text { Running with wear- } \\
\text { able parachutes in } \\
\text { two sizes }\end{array}$ & $\begin{array}{l}\text { Visceral whole body felt experi- } \\
\text { ence of drag }\end{array}$ & $\begin{array}{l}\text { Relationship between size (surface area) } \\
\text { and speed. } \\
\text { Influence of wind speed and direction } \\
\text { on speed. }\end{array}$ \\
\hline $\begin{array}{l}\text { Dropping toy para- } \\
\text { chutes of two sizes }\end{array}$ & $\begin{array}{l}\text { Observe parachutes falling at dif- } \\
\text { ferent speeds and their changing } \\
\text { shape }\end{array}$ & $\begin{array}{l}\text { Relationship between size (surface area) } \\
\text { and speed. }\end{array}$ \\
\hline $\begin{array}{l}\text { Pulling toy para- } \\
\text { chutes of two sizes }\end{array}$ & $\begin{array}{l}\text { Felt experience of moving para- } \\
\text { chutes through the air allowing for } \\
\text { immediate comparison across sizes } \\
\text { Observe parachutes } \\
\text { changing } \\
\text { shape as they moved through air }\end{array}$ & $\begin{array}{l}\text { Relationship between size (surface area) } \\
\text { and speed. } \\
\text { Shape of parachutes influenced by mo- } \\
\text { tion through air. }\end{array}$ \\
\hline
\end{tabular}

Each task consisted of experience with two differently sized parachutes. We choose to present children with only two sizes so that the observable and felt sensations children could engage with would be distinctly different, rather than on a gradation. 


\section{Wearable Parachutes}

The aim of this activity was to give children a felt sensation of resistance to their motion given the different sizes of parachutes, different levels of wind speed and different states of motion (e.g. stationary vs. in motion). The activity was designed to give children an opportunity to link their felt bodily experience to the observable variables which influenced this felt sensation: these relationships contribute to the higher order concept of air resistance. Children wore child-sized resistance parachutes adjusted to have two different surface areas (large/small) (Figure 1a). They participated in pairs and ran together from a designated start to end point twice, before switching parachute size. Children always ran into the wind, as this allowed them to experience the greatest sensation of resistance and also helped to prevent them from becoming entangled in the parachute. Movement was integral to this activity as children's task was to run between a given start and end point, and the parachutes only inflated whilst in motion - thus only through movement could children have a 'felt' experience of the effect of air resistance - a sensation of resistance to their forward momentum, which we predicted would be experienced in part as a pull sensation felt on their shoulders.
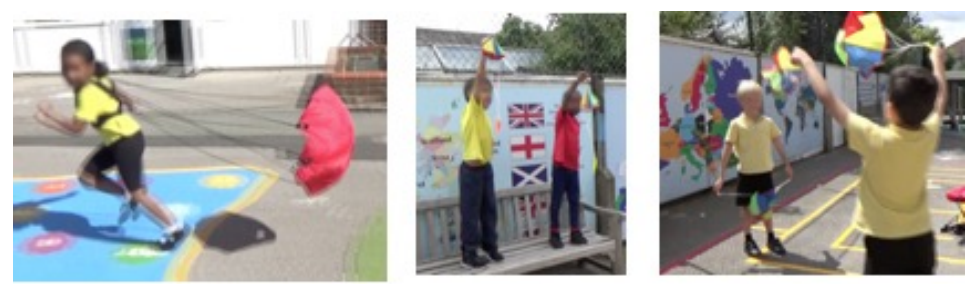

Figure 1a, 1b, 1c: Children interacting with (from left to right): a) wearable parachutes; b) dropping toy parachutes; c) pulling toy parachutes

\section{Dropping Toy Parachutes}

The aim of this activity was to provide children with an opportunity to simultaneously observe the motion of two differently sized parachutes as they travelled through the air (Figure 1b), allowing children to test and observe the impact that size has on motion/speed, and in turn the impact that motion has on the parachute shape. Children were each provided with two toy parachutes: one large and one small. They initially dropped the parachutes sequentially, and then dropped pairs of parachutes simultaneously to explore and observe how they moved through the air, since the relationship between surface area, shape and air resistance was only available through motion.

\section{Pulling Toy Parachutes}

The aim of this activity was to enable children to simultaneously feel the resistive force in their hand and arm generated by differently sized parachutes in motion, and in turn to observe how these forces and the shape of the parachutes changed as they moved through air. Using the same toy parachutes as above (Figure 1c), children were also encouraged to explore ways of moving them through air to experience how the different sized parachutes felt, moved and changed shape. 


\subsection{Evaluation of Design and Iterative Developments}

Through our analysis of the multimodal transcripts generated from the video data of interaction and interviews collected in design phase 1 , we assessed how effectively these activities had translated research theory into practice. More specifically we explored how these activities which were designed to enhance awareness of the phenomenon of air resistance through action which was congruently mapped to the underlying science ideas and fully integrated into the task, actually supported meaning making around air resistance for young children. In turn, we explored if and how young children drew on the sensations created through these activities to further support their thinking and communication. This led to us identifying which aspects of the phenomenon were being effectively communicated by the activities and which needed further mediation, leading us to iterate the design and implementation of both the interactive session and the semi-structured interview, as detailed below.

Two key issues emerged in relation to the wearable parachutes: (i) a failure to effectively communicate a relationship between parachute size and the speed at which children were able to run; and (ii) children were intrigued by their own parachute, which caused them to turn as they ran and this led to the parachute twisting and collapsing.

With the wearable parachute activity in design phase 1, we expected that when children were wearing the larger parachute their maximum running speed would be restricted. However, analysis showed that children's maximum running speed was more strongly linked to their motivation to 'win' than to the size of the parachute they were wearing. Even when they were wearing differently sized parachutes their focus was on racing, rather than 'felt' experience of speed. This was evident from children's performance during the task as well as from their reflections throughout the task and in the semi-structured interviews. Despite the fact that the larger parachute exuded a greater resistive force on children's motion, they were able to compensate for this by increasing the effort they expended. In the semi-structured interview probing children's awareness a relationship between size of parachute and children's running speed, it became apparent that the actual relationship between size of parachute and children's running speed was more complex than initially anticipated. Children tended to suggest that speed was a trait of themselves (e.g. 'I am the fastest') rather than being open to external variables, which in this particular task tended to also hold true. Partly as a result of this, the notion of speed proved to be a problematic way of exploring children's understanding. Their awareness was not drawn to 'differences' in felt kinesthetic experiences (either speed or effort) [18], since their focus was on an external goal of winning. To address this issue we changed the context of the task for design phase 2 , so that children took it in turns to run, rather than racing against one another. By removing the element of competition, we aimed to foster similar running effort with either parachute, and a better awareness of felt kinesthetic experience. Changing the context of the task in this way also meant that children could observe one another running, and the way the parachutes filled and moved whilst their peer was in motion, addressing the second issue. We expected that if children could observe their peer's parachute then this might discourage them from turning as they ran. During design phase 2 we also mentioned that turning would cause the wearable parachute to collapse. While we aimed to address this issue 
by changes to the task as described above, we also refocused our questions around the relationship between children's effort and the size of the parachute.

In terms of the toy parachute activities it became clear that children sometimes struggled to clearly observe the relationship between the size of the parachute and the speed at which it fell to the ground (with the smaller parachute travelling faster). This was not surprising, since there was only a short delay between the parachutes being released and reaching the ground (given young children's typical height). In this case the perceptual links between movement and change were not congruent enough to be meaningful [cf, 12]. This led to a researcher demonstrating the releasing of the parachutes simultaneously, as their increased height led to a longer travel time for the parachutes. To address this issue in phase 2 we provided children with a raised platform, which they could stand on to release the parachutes. This meant that they could still control the release, maintaining agency over the process, which we felt was an important factor in allowing children to focus on the sequence of events and the factors contributing to this system [20].

During the semi-structured interviews children struggled to describe their felt experience, perhaps because the experience itself was limited by a lack of wind strength on the day of implementation, but also because the questions themselves did not help children to focus on this sensation. Thus, in design phase 2 , it was vital that children had some experience of wind strength (in addition to self-generated air resistance), and increased awareness of the felt experience. To foster this, we encouraged them to engage in active reflection during the interactive experience, e.g. comparing how each run/pull felt, what had changed and what might be different in subsequent trials.

Interestingly, across the activities children's felt awareness focused on the notion of 'lift', since they often discussed their potential for flight. This notion may have emerged given that all the tasks related to parachutes, which are strongly associated with motion off the ground and in the sky, and the wearable parachute tended to lift above the level of their shoulders as they ran. This suggests the significant role of felt experience on interpretation [4]. To address this in design phase 2, we introduced an additional task using cardboard sails, with the aim of linking air-resistance and surface area, but which appeared superficially different and did not evoke any imagery of flight or motion through the sky.

Children also frequently referenced colour as a distinctive feature of the objects during and after their interactions. From design phase 2 onwards, all sets of apparatus were matched for colour and other visual features, to ensure that this variable did not interfere with other variables.

\section{Design Phase 2}

\subsection{Activity Designs}

Design phase 2 incorporated the adjustments to activities as described above, plus the addition of a task involving cardboard sails. The four activities were presented within an open-ended notion of exploring how different objects behave when moving through 
air. Thus, children (in pairs) completed four activities in the following order; Pulling toy parachutes, Dropping toy parachutes, Wearable parachutes, Cardboard sails.

\section{Pulling Toy Parachutes}

Children were provided with two toy parachutes matched for colour but differing in size, and were encouraged to explore ways of moving them through air when holding the men attached to the parachute cord. The aim of this activity was still to enable children to simultaneously feel the resistive force generated by differently sized parachutes in motion, and in turn to observe how these forces and the shape of the parachutes changed as they were moved through the air. During this phase in particular, children were asked to reflect on the felt and observed experience produced by the two parachutes. They were also further encouraged to explore ways of moving - this freedom meant that children could run, jump, rotate their arms, rotate their bodies, pull simultaneously, pull sequentially etc, leading to a range of potential sensorimotor experiences.

\section{Dropping Toy Parachutes}

Using the same two parachutes, the aim of this activity was still to provide children with an opportunity to observe the motion of two differently sized parachutes as they travelled through air, allowing children to explore the impact that size has on motion/speed, and in turn, the impact that motion has on parachute shape. Children initially dropped the parachutes sequentially, and then dropped pairs of parachutes simultaneously to explore and observe how they fell through the air: the relationship between surface area, shape and air resistance was only available through motion. To give children more opportunity for observation in this phase they were provided with a raised platform to stand on. Children were encouraged to reflect on their experiences between each release and to consider how the motion of the parachute differed and the factors which might contribute to this.

\section{Wearable Parachutes}

The aim of this activity was still to give children a felt sensation of resistance to their motion given different sizes of parachutes, different levels of wind speed and different states of motion (stationary vs. in motion). The activity was designed to give children an opportunity to link their felt bodily experience to the observable variables which influenced this felt sensation: these relationships are captured by the umbrella concept of air resistance. Children wore the same child-sized resistance parachutes adjusted to have two different surface areas (large/small) as in phase 1. They participated in pairs but ran individually from a designated start to end point twice, before switching parachutes. When stationary, children observed their peer running. Once at the end point children waited for their peer to complete the run and then both children walked back to the designated start point, with assistance from the researcher/practitioner pair. Between each run children were encouraged to reflect on their experience and to consider how the previous or next run might differ. The distance children were required to run was increased from design phase 1 to give children more opportunity to reflect on the felt experience during their run, and to try and reduce the impact of motivation on 
children's maintained speed. Children always ran into the wind to prevent them from becoming entangled in the parachute.

\section{Cardboard Sails}

The aim of this activity was to give children a different felt sensation of resistance to their motion given different sizes of 'sails', different levels of wind speed and different states of motion (stationary vs. in motion). Children were provided with two differently sized sheets of cardboard - one large and one small. They were asked to hold these sheets at the edges, with the cardboard in front of their bodies, see Figure 2. Taking it in turns children were asked to run to a designated end point. They stayed at this end point whilst their peer ran and then both children walked back to the designated start point (start and end points were the same as for the wearable parachutes). Children completed two runs before swapping 'sails'. The activity was designed to give children an opportunity to link their felt bodily experience to the observable variables which influenced this felt sensation - in this case, a more of a push sensation from in front of the body rather than a pull from behind (as with the parachutes). In particular this activity was designed to provide this felt sensation but in a visually and body positionally different context to the wearable parachutes. This activity was also designed to allow children to observe the impact of their motion on the shape of the sails during the activity. Between each run children were encouraged to reflect on their experience and to consider how the previous or next run might differ.

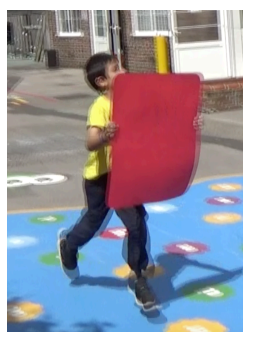

Figure 2: A child running into the wind with a 'cardboard sail'

\subsection{Evaluation of Design and Iterative Developments}

Through our analysis of the interaction and interview video data collected in design phase 2 we evaluated the design iterations implemented in terms of how effectively these activities, which were designed to promote congruent science ideas through integrated action, actually communicated these ideas to young children and in turn how young children drew on these experiences to support their thinking and communication . These showed where some modifications were effective, but also highlighted those that suggest further design iterations in both the interactive session and semi-structured interview.

\section{Effective Modifications}


During the wearable parachute activity children benefited from running individually. This led to their reflections being more focused on their own experience and their 'felt' effort required to complete a run, rather than on comparative assessments of themselves and their peers. The opportunity for children to observe their peer running meant that they were also able to describe how the parachute's shape and motion changed as it moved, and to draw out some the relationships between variables. This iteration also led to far fewer occasions where children turned during a run to observe their own parachutes, which meant children were able to have more successful experiences of running under the full influence of an inflated parachute.

During the wearable parachute activity and semi-structured interviews children were more able to describe their felt experiences than in design phase 1 . The wind strength experienced by children in this phase greatly exceeded that experienced by children in phase 1 , which is likely to have enhanced their felt experience and in turn their ability to describe this experience. Furthermore, encouraging children to make observations and reflect during the activities seemed to support their engagement with science processes (observing, describing, predicting). Furthermore, introduction of the cardboard sail activity allowed children to express their understanding of the relationship between surface area, and effort by drawing on a new embodied resource.

Giving children a raised platform to stand on as they released the toy parachutes allowed them to reflect on the motion of the parachutes and to report this with more accuracy. This removed the need for an adult to demonstrate releasing the parachutes and allowed children to be embedded within this activity. Focusing interview questions around differences in the effort required to generate motion in the various activities allowed children to express links between size (surface area) and effort. In the case of the toy parachutes children also linked these variables with speed.

Overall, these findings suggest that these activity designs had better meaning congruency, as well as more effectively bringing awareness to kinesthetic felt sensations linked to air resistance.

\section{Iterations in Design}

Children continued to talk about their potential for flight. To further address this we reordered the activities so that children engaged with the toy parachutes last, with a view to reducing emphasis on the particular 'flight' motion of these parachutes. However, we also broadened our interview questions to further probe this reported phenomenon to better identify whether children were reporting a 'felt' experience.

Few children were aware of any relationship between wind direction or even wind speed and air resistance or their felt experience. To draw attention to this variable in the final design phase we introduced a preliminary task in which children held ribbons and were asked to describe their motion. This aimed to draw children's attention to the dominant wind direction and to changes in wind speed, as these factors would influence the observed ribbon behavior and the strength of grip required by children to maintain hold of the ribbons. 


\section{Final Evaluation Phase}

The final suite of activities consisted of five activities embedded within the context of differently exploring the effects of air on movement. Children completed all five activities in a prescribed order (Ribbons, Cardboard sails, Wearable parachutes, Dropping toy parachutes, Pulling toy parachutes), with the context and structuring of the activities being largely pre-defined, while also allowing room for children to explore and investigate. This final set of activities aimed to enable children to readily identify links between size, force and effort, through both felt and observed experiences, and in the case of the toy parachutes, were also linked to speed.

Table 2: Design Phase 3 - Sensory experiences mapped to potential learning outcomes

\begin{tabular}{|c|c|c|}
\hline Activity & Key sensory experience & Potential learning outcomes \\
\hline $\begin{array}{l}\text { Running with } \\
\text { wearable para- } \\
\text { chutes in two } \\
\text { sizes }\end{array}$ & $\begin{array}{l}\text { Visceral whole body felt experience of } \\
\text { air resistance } \\
\text { Observable change in shape of para- } \\
\text { chute as another child runs }\end{array}$ & $\begin{array}{l}\text { Relationship between size (surface area) } \\
\text { and effort/speed. } \\
\text { Shape of parachutes influenced by mo- } \\
\text { tion through air. } \\
\text { Influence of wind speed and direction } \\
\text { on effort/speed. }\end{array}$ \\
\hline $\begin{array}{l}\text { Dropping toy } \\
\text { parachutes of } \\
\text { two sizes }\end{array}$ & $\begin{array}{l}\text { Observe parachutes falling at different } \\
\text { speeds and their changing shape }\end{array}$ & $\begin{array}{l}\text { Relationship between size (surface area) } \\
\text { and speed. } \\
\text { Shape of parachutes influenced by mo- } \\
\text { tion through air. Influence of wind } \\
\text { speed and direction on parachute mo- } \\
\text { tion. }\end{array}$ \\
\hline $\begin{array}{l}\text { Pulling toy } \\
\text { parachutes of } \\
\text { two sizes }\end{array}$ & $\begin{array}{l}\text { Felt experience of moving parachutes } \\
\text { through the air allowing for immediate } \\
\text { comparison across sizes } \\
\text { Observe parachutes changing shape as } \\
\text { they moved through air }\end{array}$ & $\begin{array}{l}\text { Relationship between size (surface area) } \\
\text { and effort/speed. } \\
\text { Shape of parachutes influenced by mo- } \\
\text { tion through air. }\end{array}$ \\
\hline $\begin{array}{l}\text { Running with } \\
\text { cardboard } \\
\text { 'sails' in two } \\
\text { sizes }\end{array}$ & $\begin{array}{l}\text { Visceral whole body felt experience of } \\
\text { air resistance against the sail } \\
\text { Observe change in shape of sail as they } \\
\text { move }\end{array}$ & $\begin{array}{l}\text { Relationship between size (surface area) } \\
\text { and effort/speed. } \\
\text { Shape of sail influenced by motion } \\
\text { through air. }\end{array}$ \\
\hline $\begin{array}{l}\text { Holding rib- } \\
\text { bons }\end{array}$ & $\begin{array}{l}\text { Felt experience of maintaining grip un- } \\
\text { der different wind conditions. } \\
\text { Observe direction and speed of wind }\end{array}$ & $\begin{array}{l}\text { We can observe the effect of air by see- } \\
\text { ing its influence on static objects or by } \\
\text { moving objects through air }\end{array}$ \\
\hline
\end{tabular}




\subsection{Final Evaluation}

Video analysis of interaction and interviews again focused on the effectiveness of the activities for communicating relevant aspects of air resistance. We examined how children systematically used their bodies to explore and make meaning, during the interactive tasks, as well as analysing how children's communication (including gesturing) during the semi-structured interviews incorporated aspects of their felt and wider perceptual experiences.

It was clear from children's interview data that they drew on the embodied nature of the activities to help them express their actions, observations and thoughts through gesture. Children used a range of whole-body gestures and hand gestures to capture the physicality of their experience and noticings, for example, using their whole bodies to re-enact the effort required to run with the different sized 'sails' and using their hands to show how air pushes on the parachutes, and how more air is captured by a larger parachute. These gestures allowed children to re-enact their experiences and in doing so to express the relationships they had become aware of, their developing ideas around these relationships and even support them in thinking through new problems.

The wearable parachute and cardboard 'sail' activities supported children in making connections between the size of the parachutes/sails and the amount of effort required to move these objects through air. Movement, meaningful congruency and integrated physicality was integral to the design of these tasks and to communicating these relationships. One drawback of these tasks was that, as children were embedded in the scenarios, it proved challenging for them to separate their own perceptions of themselves (in particular in terms of their speed) from the immediate experience of the task. This issue was somewhat addressed by the complementary toy parachute tasks which allowed children to consider the same variable of parachute size, but in this case to successfully map its relationship to speed.

Children tended to use the term 'heavy' to capture their observations about and sensations related to force. In this final design phase, we were confident that this was not about them reporting an absolute difference in the weight of the two parachutes when they were static, but was a 'heaviness in motion' - the felt sensation of force. This observation is not incorrect and actually captures a lot about children's sensory experience and their developing concept of force. However, given future iterations we could consider how to foster this developing understanding to help children transition between this way of thinking about 'force' and how this would map to other force scenarios. Below, we also discuss ways this might be addressed through digital design.

Children confidently discussed the pull sensation generated by the wearable parachutes, however the cardboard 'sails' task led to some apparent confusion around push forces - children sometimes appeared confused about whether they were being pushed forwards or backwards by the sail. Further iterations would be required to explore whether this confusion arises from the task itself, whether this confusion is centred around the meaning of the word 'push' or some combination of factors.

Across the activities children had their attention drawn to 'air' as a broad phenomenon - they expressed links between 'air' and the way the objects moved or the way the shape of the objects changed. In some cases children began to build a naïve theory of 
air resistance where they linked the size of the parachute with the amount of 'push' force it underwent or heaviness they felt due to air. Conveying these developing theories was greatly supported by children's use of their bodies as a mode of communication, based on their perceptuo-motor experiences.

Across all design phases children reported a sensation linked to flight. In the final evaluation phase, we became more confident that this was a genuine felt sensation as children said things like "I knew I was on the ground, but I felt like I almost might fly". This re-emphasised to us the importance of reflecting on the felt experiences that children report, beyond those which have been designed into the activities/tasks.

\section{$7 \quad$ Implications for Digital Design}

Drawing on the analysis above, in this section we outline the extent to which children use the physical 'embodied' resources provided by each activity, and begin to identify the different roles that digital technology could play in future designs. In so doing, we demonstrate how an embodied iterative design can most effectively inform digital designs, by isolating the key factors that are unsupported through physical resources alone, or that cannot be easily solved in the physical world.

Children were able to make connections between the felt experience of the effort required to run given different sized parachutes and, in some cases, linked this to ideas of air as a source of resistance. Some children started to express why a larger parachute takes more effort to move, through statements like 'it has more area and the air pushes it'. Children were able to talk about how their own motion (or that of their peers) impacted the shape of the parachutes and sails, and linked this change to ideas of how air might mediate this relationship.

However, the analysis also highlights a number of shortcomings from physical resources, which have implications for digital design. Incorporating technology into the existing physical experiences could specifically help communicate or draw attention to aspects of the science which are not effectively foregrounded. Alternatively, these activities could be presented in a more controlled or simulated environment, which might allow for alternative exploration of science ideas, and could address design implications that cannot be easily overcome in purely physical activities. Here we explore four ideas:

\subsection{Wind Speed and Direction}

Across the activities we found that very few children were aware that wind speed and direction might affect their experience, even when using ribbons to draw attention to these properties. One reason for this might have been that children were always asked to run into the wind, both to increase their felt experience and to overcome potential safety issues. Technology in the form of sensors could be incorporated into the current physical activities to detect changes in wind speed or direction, and translated into age appropriate cues, for example, a visual cue like a dial ranging from light to strong, colour change or an auditory cue that associates volume or pitch with wind speed. In 
so doing, it would aim to draw children's attention to important environmental changes which relate to and, therefore, might impact on their felt experience.

\subsection{Differentiating Sensations}

Children were able to make connections between the size of the parachutes and sails and the amount of effort needed to move through air. In the physical experience this required them to reflect across two sequential experiences and to compare the 'remembered' felt sensations generated. One issue with this approach is that other variables could change in the interim, which would affect the relationship between children's felt experience and the size of the parachute. For example, if the wind speed increased between a child's run with the large parachute and the small parachute then their felt experience could be relatively equivalent. An environment which offers more control over these variables, either through adapting the physical environment or by simulation would help address this, for example, a simulation or mixed reality environment, which combined the felt sensations children experience in the physical activities with the capacity to set and instantaneously change the variables of interest, such as wind force, parachute size. Using haptic feedback on the shoulders/ straps of the parachute may simulate and draw attention to stronger 'pull' sensation in conjunction with more wind. Or mechanisms that enable the automatic opening or closing of the parachute mid-running, would provide clearer and more immediate sensations of change. Or the size of their parachute could be adjusted during a child's run then this is likely to lead to a very compelling felt sensation of the change in air resistance, which would have an impact on their speed and the effort required to run. Allowing for particular variables to be changed instantaneously, might allow children to more readily identify links between felt sensations and given factors.

\subsection{Configuration for Variation}

If these activities were presented in a controlled or partially simulated environment then this could help to extend the learning opportunities over a wider age range. For example, older children could make predictions about how changes in wind speed, wind direction, parachute size, parachute speed or even air density would affect their speed or the effort required for them to run at a given speed. They could then test these predictions and engage in a process of enquiry learning. This could also help to extend the activities to a lower age range as the number of variables could be reduced to help communicate a simple message.

\subsection{Making the Invisible Visible}

Air is an invisible entity which we can only observe through its effect on the objects around us. Technology could enable us to make this phenomenon visible, through visualisations, which might help children to better notice the links between the movement of air (or objects movement through air) and the force that this generates. This might help them to think about this force in a different way from the notion of 'heaviness', 
that they reported in relation to our activities. This might also help them to build on the relationship between size, effort/speed and air to begin to think about how and why the size of a parachute impacts their effort/speed. This might also help children to overcome some of the confusion reported around push forces during the cardboard 'sail' activity, as the direction of net air resistance could be made visible.

\section{Conclusion}

Through a process of DBR we proposed a series of activities to communicate ideas of air resistance to 4- to 6-year-olds, which were theoretically underpinned by three key concepts: Movement, Meaning Congruency and Integrated Physicality, all of which are grounded in theories of embodied cognition. Air resistance is a phenomenon which arises due to the particular physical world which we live in. As such, physical activity within this world allows us to have direct experience of this phenomenon. We proposed a variety of tasks which drew attention to particular aspects of this experience to foster children's developing understanding of this phenomenon. Meaning congruency across these tasks was easily achieved as children's actions drew their attention to naturally occurring relationships in the physical world (e.g. the relationship between the size of an object and the amount of air resistance it is subjected to). Movement and integrated physicality was essential to all tasks as air resistance is a phenomenon which only arises due to motion of air affecting an object, or motion of an object being affected by air. As such, this topic leant itself to being supported by our three theoretical underpinnings and benefited immensely from being situated outside. One of the challenges of basing ideas about science phenomena on physical interactions with the world is the relatively minimal control one has over extraneous variables, for example wind speed. This can be problematic in educational scenarios as these extraneous variables may have a large impact on children's felt and perceived experiences, and can be a source of misconceptions - particularly if the activities themselves do not draw attention to the role of these extraneous variables. Digital design offers us opportunities to maintain the benefits of children being able to interact with the physical world through action, in meaningful ways, which can support their thinking and communication, whilst also being able to draw attention to/control aspects of the environment, which are important for children's developing meaning making around these contexts.

This research demonstrates how drawing on theory to underpin design and engaging in a process of DBR supports the translation of research in domains such as embodied cognition into practice, allows for reflection on the effectiveness of this translation and in turn can inform digital and physical design.

\section{Acknowledgements}

This material is based upon work supported under a collaboration between the National Science Foundation (NSF), the Wellcome Trust, and the Economic and Social Research Council (ESRC) via a grant from the NSF (NSF grant no. 1646940) and a grant from the Wellcome Trust with ESRC (Wellcome Trust grant no. 206205/Z/17/Z). Any 
opinions, findings and conclusions or recommendations expressed in this material are those of the author(s) and do not necessarily reflect the view of NSF, the Wellcome Trust, or ESRC. We would also like to thank Mizuki Choi and Minna Nygren for their help with data collection, the children who participated in the study, and teachers who made this research possible.

\section{References}

1. Lindgren, R., \& Johnson-Glenberg, M.: Emboldened by embodiment: Six precepts for research on embodied learning and mixed reality. Educational Researcher, 42, 445-452 (2013).

2. Wang, F. \& Hannafin, M.J.: Design-based research and technology-enhanced learning environments. Educational Technology Research and Development, 53, 5-23 (2005).

3. Tippett, C.D. \& Milford, T.: Findings from a Pre-kindergarten Classroom: Making the case for STEM in early childhood education. International Journal of Science and Mathematics Education, 15:3, 1-20 (2017)

4. Whitehead, M.(ed): Physical Literacy throughout the lifecourse. Routledge (2010)

5. Barsalou, L. W.: Grounded cognition. Annual Review of Psychology, 59, 617-645 (2008).

6. Cress, U. \& Fischer, U. \& Moeller, K. \& Sauter, C. \& Nuerk, H. C.: The use of a digital dance mat for training kindergarten children in a magnitude comparison task. Proceedings of the 9th International Conference of the Learning Sciences. 1, 105-112. (2010).

7. Abrahamson, D. \& Trninic, D.: Toward an embodied-interaction design framework for mathematical concepts. Proceedings of the 10th International Conference on Interaction Design and Children - IDC '11, 1-10 (2011).

8. Goldin-Meadow, S., Nusbaum, H., Kelly, S.D., \& Wagner, S.: Explaining math: gesturing lightens the load. Psychological science : a Journal of the American Psychological Society / APS 12, 6, 516-522 (2001).

9. Alibali, M. W. \& Nathan, M. J.: Embodiment in Mathematics Teaching and Learning: Evidence From Learners' and Teachers' Gestures, Journal of the Learning Sciences, 21:2, 247286 (2012).

10. Gallagher, S. \& Lindgren, R.: Enactive Metaphors: Learning Through Full-Body Engagement. Educational Psychology Review 27:391-404 (2015).

11. Johnson Glenberg, M.: Immersive VR and Education: Embodied Design Principles That Include Gesture and Hand Controls. Frontiers in Robotics and AI. 5, 81 (2018).

12. Hald, L. A., de Nooijer, J., van Gog, T., \& Bekkering, H.: Optimizing word learning via links to perceptual and motoric experience. Educational Psychology Review, 28, 495-522 (2016).

13. Skulmowski, A. \& Rey, D. R.: Embodied Learning: Introducing a taxonomy based on bodily engagement and task integration. Cognitive Research: Principles and Implications 3:6 (2018)

14. Wilson, R. A. \& Foglia, L.: "Embodied Cognition", The Stanford Encyclopedia of Philosophy (Spring 2017 Edition), Edward N. Zalta (ed.), https://plato.stanford.edu/archives/spr2017/entries/embodied-cognition/

15. Varela, F. J., Thompson, E., \& Rosch, E.: The embodied mind: cognitive science and human experience. Cambridge: MIT Press (1991).

16. Gallagher, S. \& Bower, M.: Making enactivism even more embodied. AVANT / Trends in Interdisciplinary Studies, 5(2), 232-247 (2014). 
17. Clark, A.: Whatever next? Predictive brains, situated agents, and the future of cognitive science. Behavioral and Brain Sciences, 36(3), 181-204.(2013).

18. Sheets-Johnson, M.: Thinking in Movement Journal of Aesthetics and Art Criticism 39(4):399 (1982)

19. Polanyi, M.: The Tacit Dimension. London: Routledge \& Kegan Paul. (1966).

20. Thomas Jha, R. L., Nygren, M.O. \& Price, S.: Exploring how children's interactions shape their gestural communication around science ideas. Science Communication (under review).

21. Wilson, A. D., \& Golonka, S. Embodied cognition is not what you think it is. Frontiers in Psychology, 4, 58. (2013).

22. Anderson, T. \& Shattuck, J.: Design-Based Research: A decade of progress in education research? Educational Researcher, 41 (1), 16-25. (2012). 